\title{
Education as a Pathway to Help Job Searching Military Veterans' Transition to Civilian Life
}

\author{
Gary Blau ${ }^{1} \&$ Glen Miller ${ }^{1}$ \\ ${ }^{1}$ Fox School of Business \& Management, Temple University, Philadelphia, USA \\ Correspondence: Gary Blau, HRM Department, Fox School of Business \& Management, Temple University, \\ Philadelphia, PA, USA. Tel: 1-215-204-6906.
}

Received: November 2, 2020

Accepted: December 4, 2020

Online Published: January 5, 2021

doi:10.20849/jed.v5i1.822

URL: https://doi.org/10.20849/jed.v5i1.822

\begin{abstract}
The transition from military to civilian life can be a difficult process. Two distinct samples of working United States military veterans were studied: combat $(n=56)$ and non-combat $(n=43)$. The goal of this study was to investigate the specific role of furthering one's education as a pathway to help job-searching military veterans in their transition to civilian life. Across both samples, veterans who were actively job searching had higher burnout and general exhaustion than veterans not actively searching. There was partial support for finding veterans who were actively job searching to be currently furthering their education, and for those currently furthering their education to perceive higher occupational alternatives. High percentages in both samples were currently going to school to further their education. The importance of education as a pathway to support military veterans making a successful transition to civilian life is discussed.
\end{abstract}

Keywords: burnout, furthering education, general exhaustion, job search, military veterans, transition to civilian life

\section{Introduction}

As United States (US) military veterans leave the military, their successful transition to civilian life can be difficult. The Pew Research Center (2019) found that only $25 \%$ of the veterans they surveyed had civilian jobs ready to immediately start after they left the military. In addition this survey found that only $16 \%$ felt that the military prepared veterans very well for their transition. A transition to civilian life scale (TCLS) for military veterans was recently published (Weiss, Rubin \& Graeser, 2019). This 15-scale identified three factors: psychosocial, economic and physical health, with nine of 15 items loading on the psychosocial factor, sample item "I participate in enjoyable recreation activities." One of the five economic items asked about education, i.e., "I can get the education I need," but this item was part of a more general economic factor which also asked about stability of finances, being happy with quality of housing, and feeling optimistic about future career. Although three factors were mentioned, reliability data was only presented for the full 15 -item scale. The goal of this study was to pursue the specific role of furthering one's education as a pathway to support job-searching military veterans in their transition to civilian life.

\subsection{Relevant Scholarship}

Burnout is an important mental health issue for many types of workers (Maslach \& Leiter, 1997). Burnout is composed of three distinct dimensions: emotional exhaustion, depersonalization, and diminished personal accomplishment. Emotional exhaustion involves feeling a lack of energy and that one's emotional resources are gone; depersonalization is described as an insensitive, callous attitude towards treating people; and diminished personal accomplishment is a tendency to self-evaluate negatively, as the individual experiences feelings of job incompetence. Most burnout research has focused on health care or mental health workers, e.g., doctors, nurses, therapists, social workers, counselors (Morse, Salybers, Rollins, Monroe-DeVita \& Pfhaler, 2012). Military-related research has also tended to focus on either military mental health professionals e.g., Ballenger-Browning et al. (2011); Kok et al., (2016) or military health care professionals, e.g., Adler et al. (2017); Smith et al. (2015). Less research has focused on testing burnout among more general military veteran samples, as this study did. At a general level, burnout has been associated with intent to quit and other turnover-related behaviors (Dreison, Luther, Bonfils, Sliter, McGrew \& Salyers, 2018). 
Education can be positively related to increased job search activity (Wanberg, Basbug, Van Hooft \& Santani, 2012). Increased education was positively related to self-reported happiness and self-rated health by Post-9/11 military veterans (Morgan, Desmarais \& Neupert, 2017). Bagby, Barnard-Brak, Thompson and Sulak (2015) found that the university-related educational experiences of 11 student veterans, which included joining social networks, and interacting with same-major student peers, and faculty contacts useful, as they transitioned from military to civilian life. In their implications for research Bagby et al. (2015) called for more research on the link between student veteran academic decisions and success outcomes, e.g., employment.

\subsection{Research Question and Research Design}

This is an exploratory study, working with smaller samples of working combat veterans and non-combat veterans. Some of the veterans in each sample were actively job searching and some were not. Some of the veterans were currently going to school to further their education and some were not. In addition, we tested if those veterans going to school perceived higher occupational alternatives then those not going to school. This led to three research questions:

RQ1 - combat veterans and non-combat veterans who are actively searching for a new job will perceive higher burnout and general exhaustion than those veterans who are not actively searching

RQ2 - combat veterans and non-combat veterans who are actively searching for a new job are more likely to be currently going to school to further their education than those who are not actively searching

RQ3 - combat veterans and non-combat veterans who are currently going to school to further their education will have higher perceived occupational alternatives than those who are not currently going to school

\section{Method}

\subsection{Participants and Procedure}

In the spring of 2019 respondents received a pre-tested Qualtrics survey link asking if they had experienced a past traumatic event (TE), and if so to then answer questions about how they experienced/dealt with this TE. There is generally very low risk when asking respondents to recall a prior TE (Ferrier-Auerbach, Erbes \& Polusny, 2009). In addition, participants could omit an item if it was too distressing to answer. Military veteran respondents, either with combat experience or not, came from several different sources. One source was the University student chapter Veterans' Association. This University was located in the Mid-Atlantic United States (US). A second source was contacts the second author had as a military veteran with different US-based veteran-oriented associations. These associations were primarily smaller non-profits formed to support veterans and their families. The survey was anonymous and took approximately 15-20 minutes to complete. Once respondents submitted this first survey, they were automatically taken to a separate second brief survey. This survey asked for an email address so participants could be randomly selected for either $\$ 50$, $\$ 20$, or $\$ 10$ multiple gift card drawings. The first item in the initial survey was a voluntary consent item, and respondents were instructed not to take the survey if they were under 18 years old. University Institutional Review Board approval was given for this project. Over a period of approximately three months, there were 320 respondents to the first survey, and 269 to the second survey. Unfortunately, 68 (21\%) of the participants to the first survey had over $90 \%$ missing data and were discarded, leaving a sample of 252 participants. Within this sample there were 153 (61\%) military veterans. Of these 153 military veterans, 99 (65\%) were currently working. These 99 participants constituted the study sample.

\subsection{Measures}

Combat versus non-combat veteran. Military veteran respondents were asked, "Are you a combat veteran?", where $1=$ yes $(\mathrm{n}=56,57 \%)$, and $2=$ no $(\mathrm{n}=43,43 \%)$.

Demographic variables. Four demographic variables were asked: gender, where $1=$ male, $2=$ female; race, where 1 = African American, $2=$ American Indian, $3=$ Asian, $4=$ Hispanic, $5=$ Multi-racial, $6=$ Pacific Islander, $7=$ White; age, indicated in years; highest education level, where $1=$ high school diploma, to $6=$ doctorate, medical, dental or law degree. The breakdown for the combat versus non-combat sample is shown in Table 1.

Burnout dimensions and general exhaustion. Each of the three burnout dimensions, emotional exhaustion, depersonalization, and diminished personal accomplishment was measured using three items. This nine-item short-form version of the Maslach burnout inventory (Maslach \& Leiter, 1997) has been used in prior research (McManus, Keeling \& Paice, 2004). A sample item for emotional exhaustion is, "I feel emotionally drained from my work"; and for depersonalization, "I have become more callous/insensitive towards people since I took this 
job". A 7-point frequency response scale was used, where $1=$ never, $2=$ a few times a year, $3=$ once a month or less, $4=$ a few times a month, $5=$ once a week, $6=$ a few times a week, and $7=$ every day. A sample item for personal accomplishment was, "I deal very effectively with any people-related problems at work". Following prior research (Blau, Tatum \& Goldberg, 2013) these three personal accomplishment items were recoded so that $1=$ every day and $7=$ never, and the scale was retitled as diminished personal accomplishment. Coefficient alpha for these scales were: emotional exhaustion $=.80$, depersonalization $=.70$, and diminished personal accomplishment $=.65$. These reliabilities are consistent with prior research (Blau et al., 2013; Maslach \& Leiter, 1997). General exhaustion was adapted from (Moore, 2000) and measured using two-items. A sample item was "I feel exhausted from life in general." A 7-point response scale, $1=$ strongly disagree to $7=$ strongly agree was used. The coefficient alpha for this scale was .90 .

Active job search. One item asked, "I am actively searching for a new or different paid work situation", where 1 $=$ yes, $2=$ no.

Currently going to school. One item asked, “Are you currently going to school to further your education”, where $1=$ yes, $2=$ no.

Perceived occupational alternatives. A three-item scale was used (Blau, 2003). A sample item was "given my background and experience, I have other occupational alternatives." A seven-point response scale was used, where 1 = strongly disagree to $7=$ strongly agree. Coefficient alpha was .89 , which is consistent with prior research (Blau, 2003).

\subsection{Data Analyses}

All data were analyzed using SPSS-PC version 25 (SPSS, 2015). Frequency breakdowns for the combat versus non-combat samples were given for the demographic variables, followed by a correlation matrix for continuous variables using the combined samples. Paired sample t-tests were used to test for differences between the three burnout dimensions and general exhaustion. Independent sample t-tests on the burnout dimensions and general exhaustion were used for combat versus non-combat samples, comparing those actively job searching versus not (RQ1). Chi-square analyses were done for combat versus non-combat samples, comparing those actively job searching versus not against those currently going to school versus not (RQ2). Finally, independent sample $\mathrm{t}$-tests were done on perceived occupational alternatives for combat versus non-combat samples comparing those currently going to school versus not. (RQ3) To determine statistical significance, a cutoff of $p<.10$ (two-tailed) was used. Prior research (Hopkins, Marshall, Batterham \& Hanin, 2008, p.6) argued that $p=.10$, with a 90\% confidence is "an appropriate default level of confidence."

\section{Results}

\subsection{Frequency Breakdown of Demographics for Combat Versus Non-combat Sample}

Table 1 presents the frequency breakdown of demographics for the combat versus non-combat sample. Both samples are predominantly white, male, with a four-year degree being the most frequent category for highest education level. The most frequent age category for combat veterans was 33 to 39 , while for non-combat veterans it was 19 to 25 .

Table 1. Frequency statistics for demographic variables - combat and non-combat veteran samples

\begin{tabular}{lll}
\hline Variable & Combat Sample $(\mathrm{n}=56)$ & Non-combat Sample $(\mathrm{n}=43)$ \\
\hline Gender & $\mathrm{n}=47(84 \%)$ & $\mathrm{n}=29(67 \%)$ \\
$\quad$ Male & $\mathrm{n}=9(16 \%)$ & $\mathrm{n}=13(30 \%)$ \\
$\quad$ Female & $\mathrm{n}=0$ & $\mathrm{n}=1(3 \%)$ \\
\multicolumn{1}{c}{ Did not identify } & & \\
\hline Race & $\mathrm{n}=3(5 \%)$ & $\mathrm{n}=5(11 \%)$ \\
African American & $\mathrm{n}=0$ & $\mathrm{n}=0$ \\
American Indian & $\mathrm{n}=4(7 \%)$ & $\mathrm{n}=2(5 \%)$ \\
Asian & $\mathrm{n}=4(7 \%)$ & $\mathrm{n}=2(5 \%)$ \\
Hispanic & & \\
\hline
\end{tabular}




\begin{tabular}{lll}
\hline Multi-racial & $\mathrm{n}=5(9 \%)$ & $\mathrm{n}=4(9 \%)$ \\
Pacific Islander & $\mathrm{n}=0$ & $\mathrm{n}=0$ \\
White & $\mathrm{n}=40(71 \%)$ & $\mathrm{n}=30(70 \%)$
\end{tabular}

\begin{tabular}{lll}
\hline $\begin{array}{l}\text { Age (collapsed into categories for } \\
\text { space) }\end{array}$ & \\
$19-25$ & $\mathrm{n}=2(4 \%)$ & $\mathrm{n}=9(21 \%)$ \\
$26-32$ & $\mathrm{n}=11(20 \%)$ & $\mathrm{n}=8(19 \%)$ \\
$33-39$ & $\mathrm{n}=22(38 \%)$ & $\mathrm{n}=7(16 \%)$ \\
$40-46$ & $\mathrm{n}=6(11 \%)$ & $\mathrm{n}=7(16 \%)$ \\
$47-53$ & $\mathrm{n}=9(15 \%)$ & $\mathrm{n}=5(12 \%)$ \\
$54-60$ & $\mathrm{n}=2(4 \%)$ & $\mathrm{n}=2(5 \%)$ \\
$61-67$ & $\mathrm{n}=2(4 \%)$ & $\mathrm{n}=4(9 \%)$ \\
$68-74$ & $\mathrm{n}=2(4 \%)$ & $\mathrm{n}=1(2 \%)$ \\
75 or more & $\mathrm{n}=0$ & $\mathrm{n}=0$ \\
& & $\mathrm{n}=1(2 \%)$ \\
\hline Highest Education Level & $\mathrm{n}=0$ & $\mathrm{n}=10(23 \%)$ \\
High School Diploma & $\mathrm{n}=4(7 \%)$ & $\mathrm{n}=2(5 \%)$ \\
Some College & $\mathrm{n}=6(11 \%)$ & $\mathrm{n}=16(37 \%)$ \\
Associate Degree & $\mathrm{n}=21(37 \%)$ & $\mathrm{n}=10(23 \%)$ \\
Four Year Degree & $\mathrm{n}=17(30 \%)$ & $\mathrm{n}=4(10 \%)$ \\
Masters Degree & $\mathrm{n}=8(15 \%)$ & \\
Doctorate, Medical, & & \\
Dental or Law Degree & & \\
&
\end{tabular}

\subsection{Means, Standard Deviations and Correlations for Continuous Variables for Combined Sample}

Table 2 presents the full sample means, standard deviations and correlations for continuous variables for the combined samples. The means for the three burnout dimensions and general exhaustion were not high, while the mean for Perceived Occupational Alternative was higher. Paired sample t-tests found significant mean differences $(p<.05)$ such that General Exhaustion was higher than Emotional Exhaustion, which was higher than Diminished Personal Accomplishment, which was higher than Depersonalization. Positive correlations between the three burnout dimensions were consistent with prior research (Blau et al., 2013). The highest correlation was between general exhaustion and emotional exhaustion, $r(97)=.65, p<.01$. This correlation indicated $(.65)^{2}=42 \%$ overlap, which indicated sufficient independence for both variables to be used separately in subsequent analyses (Stevens, 1996). 
Table 2. Full sample - means, standard deviations, and correlations for continuous variables

\begin{tabular}{|c|c|c|c|c|c|c|c|c|}
\hline Measure & $\mathrm{M}^{\mathrm{d}}$ & $\mathrm{SD}$ & 1 & 2 & 3 & 4 & 5 & 6 \\
\hline 1. Age $^{\mathrm{a}}$ & 28.04 & 16.98 & $(--)$ & & & & & \\
\hline 2. Emotional Exhaustion ${ }^{\mathrm{b}}$ & $3.27^{\mathrm{f}}$ & 1.62 & -.11 & $(---)$ & & & & \\
\hline 3. Depersonalization ${ }^{\mathrm{b}}$ & $2.14^{\mathrm{h}}$ & 1.29 & $-.28 * *$ & $.49 * *$ & $(---)$ & & & \\
\hline 4. Diminished Personal Accomplishment ${ }^{\mathrm{b}}$ & $2.82^{\mathrm{g}}$ & 1.50 & -.13 & .17 & .16 & $(---)$ & & \\
\hline 5. General Exhaustion ${ }^{\mathrm{c}}$ & $3.66^{\mathrm{e}}$ & 1.81 & .01 & $.65 * *$ & $.30 * *$ & $.29 * *$ & $(---)$ & \\
\hline 6. Perceived Occupational Alternatives ${ }^{\mathrm{c}}$ & 4.85 & 1.94 & -.12 & -.10 & .03 & $-.26^{* *}$ & $-.27 * *$ & $(---)$ \\
\hline \multicolumn{9}{|l|}{$(\mathrm{n}=99) * \mathrm{p}<.05 ; * * \mathrm{p}<.01$ (two-tailed) } \\
\hline $\begin{array}{l}{ }^{b} \text { Emotional Exhaustion, Depersonalizat } \\
{ }^{c} \text { General Exhaustion, Perceived Occupa } \\
{ }^{d} \text { Means with different superscripts, } \\
\text { Exhaustion higher than Emotional Ex } \\
\text { which is higher than Depersonalization }\end{array}$ & $\begin{array}{l}\text { n, Dimi } \\
\text { onal Alt } \\
\text { g. h are } \\
\text { ustion, } \\
<.05 \text { le }\end{array}$ & $\begin{array}{l}\text { ished } \mathrm{P} \\
\text { rnatives } \\
\text { ignifica } \\
\text { vhich is }\end{array}$ & $\begin{array}{l}\text { sonal Ac } \\
1=\text { stron } \\
\text { tly diffe } \\
\text { higher } t\end{array}$ & $\begin{array}{l}\text { omplish } \\
\text { ly disag } \\
\text { nt usin } \\
\text { an Dim }\end{array}$ & $\begin{array}{l}\text { ent, } 1= \\
\text { ee to } 7= \\
\text { a paire } \\
\text { ished } \mathrm{F}\end{array}$ & $\begin{array}{l}\text { Never to } \\
\text { strongly } \\
\text { sample } \\
\text { ersonal }\end{array}$ & $\begin{array}{l}=\text { Every } \\
\text { gree } \\
\text { t-test, G } \\
\text { complis }\end{array}$ & \\
\hline
\end{tabular}

\subsection{Tests of Research Questions}

RQ1 stated that combat veterans and non-combat veterans who are actively searching for a new job will perceive higher burnout and general exhaustion than those veterans who are not actively searching. The results are shown in Table 3. There is a clear pattern of higher means on all three burnout dimensions and general exhaustion for those combat and non-combat veterans who are actively searching for jobs versus those who are not actively searching. Most of the mean differences are significantly different, providing overall support for the first research question.

Table 3. Independent sample t-tests comparing burnout dimensions and general exhaustion for combat veterans and non-combat veterans who are actively searching for a new job versus not actively searching

\begin{tabular}{|c|c|c|c|c|c|c|}
\hline & \multicolumn{3}{|c|}{ Combat Veterans } & \multicolumn{3}{|c|}{ Non-combat Veterans } \\
\hline & $\begin{array}{l}\text { Active } \\
\text { Search }\end{array}$ & $\begin{array}{l}\text { Not Active } \\
\text { Search }\end{array}$ & & $\begin{array}{l}\text { Active } \\
\text { Search }\end{array}$ & $\begin{array}{l}\text { Not Active } \\
\text { Search }\end{array}$ & \\
\hline & $(n=21)$ & $(n=35)$ & & $(n=18)$ & $(n=25)$ & \\
\hline Variable & $\mathrm{M}(\mathrm{SD})$ & $\mathrm{M}(\mathrm{SD})$ & $t$-value & $\mathrm{M}(\mathrm{SD})$ & $\mathrm{M}(\mathrm{SD})$ & t-value \\
\hline 1. Emotional Exhaustion & $3.58(1.89)$ & $3.05(1.44)$ & 1.18 & $3.71(1.95)$ & $2.41(1.01)$ & $2.51 *$ \\
\hline 2. Depersonalization & $2.85(1.79)$ & $1.86(1.11)$ & $2.24 *$ & $2.22(1.10)$ & $1.58(.72)$ & $2.08^{*}$ \\
\hline \multicolumn{7}{|l|}{ 3. Diminished Personal } \\
\hline Accomplishment & $3.00(1.41)$ & $2.35(1.38)$ & $1.66+$ & $3.67(1.83)$ & $2.53(1.08)$ & $2.30^{*}$ \\
\hline 4. General Exhaustion & $4.31(1.94)$ & $3.20(1.65)$ & $2.62 *$ & $4.36(1.89)$ & $3.30(1.88)$ & $2.04 *$ \\
\hline
\end{tabular}

$+p<.10 ; * p<.05$ (two-tailed)

RQ2 stated that combat veterans and non-combat veterans who are actively searching for a new job are more likely to be currently going to school to further their education than those who are not actively searching. The results are shown in Table 4 . The Chi-square values show that there is statistical support for combat veterans, but not non-combat veterans. Thus RQ2 was only partially supported. However, the high percentages of both combat veterans $(40 / 56=71 \%)$ and non-combat veterans $(35 / 43=81 \%)$ going back to school to further their education is important to note below. 
Table 4. Chi-Square tests comparing combat and non-combat veterans who are actively job searching versus not and who are currently going to school to further their education versus not

\begin{tabular}{|c|c|c|c|c|c|}
\hline & \multicolumn{3}{|c|}{ Combat Veterans } & \multicolumn{2}{|c|}{ Non-combat Veterans } \\
\hline & \multicolumn{2}{|c|}{ Going to School } & & \multicolumn{2}{|c|}{ Going to School } \\
\hline & Yes & No & & Yes & No \\
\hline Yes & 19 & 1 & Yes & 15 & 2 \\
\hline Actively & & & & & \\
\hline Job Searching & & & & & \\
\hline No & 21 & 15 & No & 20 & 6 \\
\hline
\end{tabular}

RQ3 stated that combat veterans and non-combat veterans who are currently going to school to further their education will have higher perceived occupational alternatives than those who are not currently going to school. Although the perceived occupational means were higher for both combat and non-combat veterans going to school versus those who were not, only the mean difference for non-combat veterans was statistically significant as shown below in Table 5. Thus, there was partial support for RQ3.

Table 5. Independent sample t-tests comparing perceived occupational alternatives for combat veterans and non-combat veterans who are currently going to school to further their education versus those who are not going

\begin{tabular}{|c|c|c|c|c|c|c|}
\hline & \multicolumn{3}{|l|}{ Combat Veterans } & \multicolumn{3}{|c|}{ Non-combat Veterans } \\
\hline & Going to School & Not Going & & Going to School & Not Going & \\
\hline & $(n=40)$ & $(n=16)$ & & $(n=35)$ & $(n=8)$ & \\
\hline Variable & $\mathrm{M}(\mathrm{SD})$ & $\mathrm{M}(\mathrm{SD})$ & t-value & $\mathrm{M}(\mathrm{SD})$ & $\mathrm{M}(\mathrm{SD})$ & t-value \\
\hline $\begin{array}{l}\text { Perceived } \\
\text { Occupational }\end{array}$ & & & & & & \\
\hline Alternatives & $5.44(1.61)$ & $5.00(1.74)$ & .90 & $4.72(2.05)$ & $2.33(1.03)$ & $4.12 * *$ \\
\hline
\end{tabular}

\section{Discussion}

The results of this showed that both combat and non-combat veterans who were actively searching for a new job perceived higher burnout and general exhaustion than veterans who were not actively searching. This finding is consistent with research using more general work samples (Dreison et al., 2018). Across both study samples, emotional exhaustion was higher than the other two burnout dimensions of diminished personal accomplishment and depersonalization. Burnout has not been as frequently studied with general military veteran samples as done here versus other military samples, such as mental health professionals (Kok et al., 2016) or health care professionals, e.g., Adler et al. (2017). In addition, general exhaustion was higher than emotional exhaustion. These results indicate that veterans searching for new jobs were not as "happy" as those not searching. There was partial support for veterans who were actively job searching to be currently going to school to further their education, and veterans currently going to school having higher perceived occupational alternatives. Good initial job placement as they left the military was found to be a challenging issue for many veterans who felt they had less than adequate preparation for this transition (Pew Research Center, 2019). The Pew study also found that officers were twice as likely as enlisted personnel to have a job lined up when they left the military. Although we don't know the departing rank or civilian work history of the veterans studied here, the results did show that those with higher perceived burnout and general exhaustion were more likely to be actively job searching.

Providing resources to all US veterans, e.g., resume building, interviewing, and technological search skills, regardless of rank, is important as they prepare to transition to civilian life. Anecdotal evidence from employers and veterans suggest that many veterans have significant leadership and teamwork skills that may not be understood by employers without a military work history. To help overcome this veteran skill - employer need gap, the Department of Labor (2019) challenged organizations to create a job-matching software tool to 
eventually be added to the Employment Workshop curriculum for all transitioning service members. Providing such a tool with stronger skill/need matching should hopefully enable veterans to not only find an initially satisfying civilian job placement, but to change jobs more easily as needed.

Prior research has found university-related educational experiences to be helpful to transitioning veterans (Bagby et al., 2015). The results of this study support going back to school to further one's education as one specific pathway to help the active job search process and increase the perception of occupational alternatives. This study found high percentages of both samples were currently going back to school to further their education. Although we don't know the level of degree being sought, inspection of the highest education level reported shows that some veterans had still not attained a four-year degree, and those that had their baccalaureate were perhaps seeking a higher-level degree. The United States Department of Veterans Affairs (2016) estimated that by 2021, there will be about 5.1 million veterans who were on active duty after September 10, 2001 (Post-9/11 Veterans). Of those Post-9/11 Veterans, it was further estimated that only $32 \%$ will have a bachelor's degree or higher. Prior studies of veterans returning to college have typically focused on student transition concerns, much of which were related to policies that complicated re-enrollment, such as lapses in student insurance, cancellation of financial aid, or being off-sequence for infrequently offered courses (e.g., Rumann \& Hamrick, 2010). Other studies have argued the need for increased support for returning-to-college veterans, such as having access to student veterans' organizations, additional mentoring, or veterans' resource centers (e.g., Evans, Pellegrino, \& Hoggan, 2015).

These results suggest that furthering one's education can be a useful track to support veterans transitioning to civilian life. To the authors' knowledge, such a measure of furthering one's education has not been tested before. Although education is mentioned in prior work on veterans transitioning to civilian life (Weiss et al., 2019), this item was part of a more general "economic" factor, and focused on veterans perceiving they can get the education needed, versus asking if they were currently going to school. Getting the education needed can imply having necessary financial resources, which can be an important prerequisite to going back to school (Bagby et al., 2015). Using such an item separately in future research, and not as part of a general scale (Weiss et al., 2019), could be beneficial. It would be interesting to study the type of major veterans pursue when they go back to college, while taking advantage of tuition benefits earned as a veteran. For example, prior research has classified college majors as being more intrinsically (I) versus more extrinsically (E) oriented (Yu \& Levesque-Bristol, 2018). Intrinsic motivation involves doing a task for its inherent satisfaction, while extrinsic motivation focuses on doing the same task to achieve external rewards, such as compensation (Ryan \& Deci, 2000). Business students with such majors as accounting, business management, finance, and marketing, emphasize maximizing profits, and have a higher extrinsic value orientation than education-related majors, who are more intrinsically motivated (Vansteenkiste, Duriez, Simons \& Soenens, 2006). Yu and Levesque-Bristol (2018) asserted that all science-related majors, including natural sciences, such as biology, chemistry and physics, as well as social sciences, should be more intrinsically motivated versus engineering and technology-related majors, which would tend to attract more extrinsically motivated students due to higher paying jobs. Finding the right major, leading to a stronger job fit after graduation, would be important to help such veterans make a smoother transition back to civilian life. This reinforces the importance of giving support, especially appropriate academic advising, to returning-to-college veterans (Evans et al., 2015).

\subsection{Limitations and Future Research}

This research has limitations. One is the threat to internal validity, i.e., other explanations for the results found (Stevens, 1996). Several issues which affect internal validity include: history; maturation; subject selection bias; and instrumentation (Stevens, 1996). As an example of history, we don't know the job history of participating veterans. We only asked if they were currently searching for a new paid work situation. Maturation is an issue because of the respondent heterogeneity in age, although age only showed a significant relationship to the burnout dimension of depersonalization. For selection bias, participants self-selected into taking the survey, based on prior experience with some type of traumatic event. The authors approached different organizational sources, but had no control over which participants took the survey. Furthermore, the economic reward of multiple cash gift card drawings had an adverse effect and contributed to $21 \%$ of the sample only filling out a few survey items (over $90 \%$ missing data) to then gain gift drawing eligibility. The data from these participants had to be discarded. This further reduced the already smaller sample sizes of combat and non-combat veterans. Instrumentation is important to note. Collecting all the data at once in a survey limits causal inference. Both the active job search and currently going to school items were asked in a Yes-No format. This dichotomous measurement limited the data analyses that could be done with both. Although the short-form version of the Maslach scale has been successfully used (McManus et al., 2004), a longer version measure of burnout (Maslach 
\& Leiter, 1997), as well as general exhaustion (Moore, 2000), might have affected the results found. All measures were self-report so method bias is a concern. However, the one-factor test results showed that when using all items in a principal components analysis (PCA), eight factors had an eigenvalue of over 1 and the first factor accounted for only $20 \%$ of the total variance. Therefore, if this first factor measures method bias, it is not a severe limitation (Podsakoff, MacKenzie, Lee \& Podsakoff, 2003).

\section{Conclusion}

This study's goal, i.e., pursuing the specific role of furthering one's education as a pathway to help job-searching US military veterans in their transition to civilian life, was unique in the sense of little prior research. As such the results found are in need of follow-up to test the generalizability of these initial findings. Future military samples measuring veterans going back to school to further their education would ideally have more heterogeneous demographics, e.g., gender, race, branch of service, as well as investigating type of college major pursued. Distinguishing between officers versus enlisted personnel transitioning to civilian life would also be useful (Pew Research Center, 2019). The findings here also draw attention to less satisfied (greater perceived burnout) veterans being more active in their job search. This points out the importance of veterans not only being ready for their first civilian job when leaving the military but also for successive civilian jobs if/when necessary.

\section{References}

Adler, A. B., Adrian, A. L., Hemphill, M., Scaro, N. H., Sipos, M. L., \& Thomas, J. L. (2017). Professional stress and burnout in U. S. military personnel deployed to Afghanistan. Military Medicine, 182(2/4), e1669-1676. https://doi.org/10.7205/MILMED-D-16-00154

Bagby, J. H., Barnard-Brak, L., Thompson, L. W., \& Sulak, T. N. (2015). Is anyone listening? An ecological systems perspective on veterans transitioning from the military to academia. Military Behavioral Health, 3(4), 219-229. https://doi.org/10.1080/21635781.2015.1057306

Ballenger-Brown, K. K., Schmitz, K. J., Rothacker, J. A., Hammer, P. S., Webb-Murphy, J. A., \& Johnson, D. C. (2011). Predictors of burnout among military mental health providers. Military Medicine, 176(3), 253-260.

Blau, G. (2003). Testing a four-dimensional structure of occupational commitment. Journal of Occupational and Organizational Psychology, 76, 469-488. https://doi.org/10.1348/096317903322591596

Blau, G., Tatum, D. S., \& Goldberg, C. W. (2013). Exploring correlates of burnout dimensions in a sample of psychiatric rehabilitation practitioners: A cross-sectional study. Psychiatric Rehabilitation Journal, 36(3), 166-172. https://doi.org/10.1037/prj0000007

Department of Labor. (2019). Veterans' employment challenge. Retrieved November 11, 2020, from https://www.challenge.gov/challenge/vets-match/

Dreison, K. C., Luther, L., Bonfils, K. A., Sliter, M. T., McGrew, J. H., \& Salyers, M. P. (2018). Job burnout in mental health providers: A meta-analysis of 35 years of intervention research. Journal of Occupational Health Psychology, 23(1), 18-30. https://doi.org/10.1037/ocp0000047

Evans, J. L., Pellegrino, L., \& Hoggan, L. (2015). Supporting veterans at the community college: A review of the literature. The Community College Enterprise, 2(1), 47-65. Retrieved from https://eric.ed.gov/?id=EJ1079760

Ferrier-Auberach, A. G., Erbes, C. R., \& Polusny, M. A. (2009). Does trauma survey research cause more distress than other types of survey research?. Journal of Traumatic Stress, 22(4), 320-323. https://doi.org/10.1002/jts.20416

Hopkins, W. G., Marshall, S. W., Batterham, A. M., \& Hanin, J. (2008). Progressive statistics for studies in sports medicine and exercise science. Medicine \& Science in Sports \& Exercise, 40, 1-10. https://doi.org/10.1249/MSS.0b013e31818cb278

Kok, B. C., Herrell, R. K., Grossman, S. H., West, J. C., \& Wilk, J. E. (2016). Prevalence of professional burnout among military mental health service providers. Psychiatric Services, 67(1), 137-140. https://doi.org/10.1176/appi.ps.201400430

Maslach, C., \& Leiter, M. P. (1997). The truth about burnout: How organizations cause personal stress and what to do about it. San Francisco, CA: Jossey-Bass.

McManus, I. C., Keeling, A., \& Paice, E. (2004). Stress, burnout and doctors' attitudes to work are determined by personality and learning style: A twelve year longitudinal study of UK medical graduates. $B M C$ Medicine, 2(29), 1-12. https://doi.org/10.1186/1741-7015-2-29 
Moore, J. (2000). Why is this happening? A causal attribution approach to work exhaustion consequences. Academy of Management Review, 25(2), 335-49. https://doi.org/10.2307/259017

Morgan, J. K., Desmarais, S. L., \& Neupert, S. D. (2017). An integrated model of health and happiness among post-9/11 military veterans. Military Behavioral Health, 5(3), 236-244. https://doi.org/10.1080/21635781.2017.1310681

Morse, G., Salyers, M., Rollins, A., Monroe-DeVita, M., \& Pfahler, C. (2012). Burnout in mental health services: A review of the problem and its remediation. Administrative Policy in Mental Health and Mental Health Services Research, 39, 341-352. https://doi.org/10.1007/s10488-011-0352-1

Pew Research Center. (2019). The American veteran experience and the Post-9/11 generation. Retrieved from https:/www.pewsocialtrends.org/wp-content/uploads/sites/3/2019/09/PSDT.10.09.19_veteransexperiences_ full.report.pdf

Podsakoff, P., Mackenzie, S., Lee, J., \& Podsakoff, N. (2003). Common method biases in behavioral research: Critical review of the literature and recommended remedies. Journal of Applied Psychology, 88(5), 879-903. https://doi.org/10.1037/0021-9010.88.5.879

Rumann, C. B., \& Hamrick, F. A. (2010). Student veterans in transition: re-enrolling after war zone deployments. The Journal of Higher Education, 81(4), 431-458. https://doi.org/10.1080/00221546.2010.11779060

Ryan, R. M., \& Deci, E. L. (2000). Self-determination theory and the facilitation of intrinsic motivation, social development, and well-being. American Psychologist, https://doi.org/10.1037110003-066X.55.1.68

Smith, H. A., Stephenson, J. A., Morrow, C. E., Haskell, J. S., Staal, M., Bryan, A. O., \& Bryan, C. J. (2015). Factors associated with burnout among active duty versus National Guard/Reserve U. S. Air Force pararescuemen. Military Behavioral Health, 3(1), 5-13. https://doi.org/10.1080/21635781.2014.995245

SPSS-PC (Version 25). (2015). Statistical package for the social sciences. Chicago: IBM.

Stevens, J. (1996). Applied multivariate statistics for the social sciences (2nd ed.). Mahwah, NJ: Lawrence Erlbaum.

United States Department of Veterans Affairs. (2016). Profile of Post-9/11 Veterans: 2016. National Center for $\begin{array}{lllll}\text { Veterans Analysis } & \text { Statistics, } & \text { Retrieved } & \text { from }\end{array}$ https://www.va.gov/vetdata/docs/SpecialReports/Post_911_Veterans_Profile_2016.pdf

Vansteenkiste, M., Duriez, B., Simons, J., \& Soenens, B. (2006). Materialistic values and well-being among business students: Further evidence of their detrimental effect. Journal of Applied Social Psychology, 36(12), 2892-2908. https://doi.org/10.1111/j.0021-9029.2006.00134.x

Wanberg, C., Basbug, G., Van Hooft, E. A. J., \& Samtami, A. (2012). Navigating the black hole: Explicating layers of job search context and adaptational responses. Personnel Psychology, 65, 887-926. https://doi.org/10.1111/peps.12005

Weiss, E. L., Rubin, A., \& Graeser, M. (2019). Transitioning to civilian life scale (TCLS): Development, reliability, and validity. Military Behavioral Health. https://doi.org/10.1080/21635781.2018.1540317

Yu, S., \& Levesque-Bristol, C. (2018). Are students in some college majors more self-determined in their studies than others?. Motivation and Emotion, 42, 831-851. https://doi.org/10.1007/s11031-018-9711-5

\section{Copyrights}

Copyright for this article is retained by the author(s), with first publication rights granted to the journal.

This is an open-access article distributed under the terms and conditions of the Creative Commons Attribution license (http://creativecommons.org/licenses/by/4.0/). 